\section{Stimulus relevancy and transfer of perceptual learning*}

\author{
THOMAS L. BENNETT, BARRY S. ANTON, and LYNN LEVITT \\ Colorado State University; Fort Collins, Colo. 80521
}

Albino rats reared in a visually sparse environment were preexposed to stimuli which varied in their degree of relevancy to the to-be-discriminated stimuli, an equilateral triangle and a circle. It was found that for early experience with stimuli to facilitate perceptual learning, the preexposed stimuli must be of the same general class as the to-be-discriminated stimuli. These findings suggested that the positive transfer effect which follows preexposure to stimuli results from identifying specific aspects of the stimuli rather than being due to a more general process of simply having had stimulus experience.
In light of a great deal of experimental evidence, it is now well established that early experience with stimuli enhances their later discriminability (e.g., Bennett \& Ellis, 1968; Gibson \& Walk, 1956; Kerpelman, 1965). However, the basis for the positive transfer effects has remained obscure. One issue deals with the question of what is learned in the early environment that transfers to the facilitation in discrimination learning following early experience result from identifying a specific pattern or rather from some more general process of just having had stimulus experience?

The present study examined this issue by exposing animals to stimuli which varied in their degree of relevancy to the to-be-discriminated stimuli, an equilateral triangle and a circle. Four groups of animals were employed. Group I (identical) received early experience with cutout circles and equilateral triangles; Group R (relevant) was preexposed to ellipses and isosceles triangles; and Group NR (nonrelevant) had early experience with irregularly shaped crosses and struniforms (a random shape made up of curved lines). A control group (Group C) was not preexposed to any shapes. At 90 days of age, all Ss were trained on a circle-equilateral triangle discrimination as a test for the effects of the early-experience conditions. METHOD

Charles River albino rats served as Ss. The animals were born and reared in cages which were placed in compartments painted flat white. The opening of each compartment was $2 \mathrm{ft}$ from the white wall of the room in which the animals were housed. Food and water were available ad lib; Ss

* This research was supported by Grant MH 20076-01 from the National Institute of Mental Health. Requests for reprints should be addressed to Thomas $L$. Bennet $t$, Department of Psychology, Colorado State Universitv, Fort Collins, Colo. 80521 . discrimination task. That is, does the nursed ad lib until the age of 21 days. Thus, during the rearing period, the visual field of the animals consisted of the cage, the compartment walls and ceiling, the water bottle, the cage mates, and the stimuli for the experimental groups. Each of the compartments was illuminated from 7:00 a.m. until 6:00 p.m.

The experiment was conducted in two stages. Stage 1 began at 21 days of age when the animals were weaned, separated as to sex, marked for identification, and assigned to one of the four early-experience conditions. As indicated, Group I $(\mathrm{N}=11)$ was preexposed to circles and equilateral triangles, Group $\mathrm{R}(\mathrm{N}=13)$ to ellipses and isosceles triangles, Group NR $(\mathrm{N}=11)$ to struniforms and irregularly shaped crosses, and Group $C(N=11)$ received no stimulus preexposure. For the groups that received early experience with forms, the stimuli were constructed from 1/8-in.-thick black Plexiglas. The stimuli were suspended from the cage ceiling by means of a wire. There was one cutout to each wall, and their position was

At the age of 90 days, the rats entered Stage 2 and they were given 5 days of discrimination pretraining. Following pretraining, the animals of all groups were given a circle-equilateral triangle discrimination problem as a test of the effects of the preexposure conditions. The testing apparatus was a Grice discrimination box as modified by Gibson \& Walk (1956). Discrimination training and pretraining procedures were identical to those employed by Bennett \& Ellis (1968). The Ss were run to a criterion of 18 out of 20 correct responses, with the last 10 consecutive responses correct, or for a total of 300 trials; animals were given 10 trials/day.

RESULTS AND DISCUSSION

The principle findings obtained in the discrimination-learning task are presented in Fig. 1, which shows a plot of the percentage of correct responses as a function of successive trial blocks for the four conditions of the experiment. Inspection of this figure indicates that the slopes of the performance curves for the three groups that received stimulus preexposure were roughly equivalent after the animals departed from a chance level of responding. The learning rate of the no-earlyexperience control group, on the other hand, appears to have been more gradual. Inspection of Fig. 1 further indicates that the performance of Groups $I$ and $R$ on the discrimination task were similar after Trial Block 8 and, furthermore, that their performance was superior to that of Groups NR and C. The learning curve of Group NR is of particular interest. rotated daily around the cage.

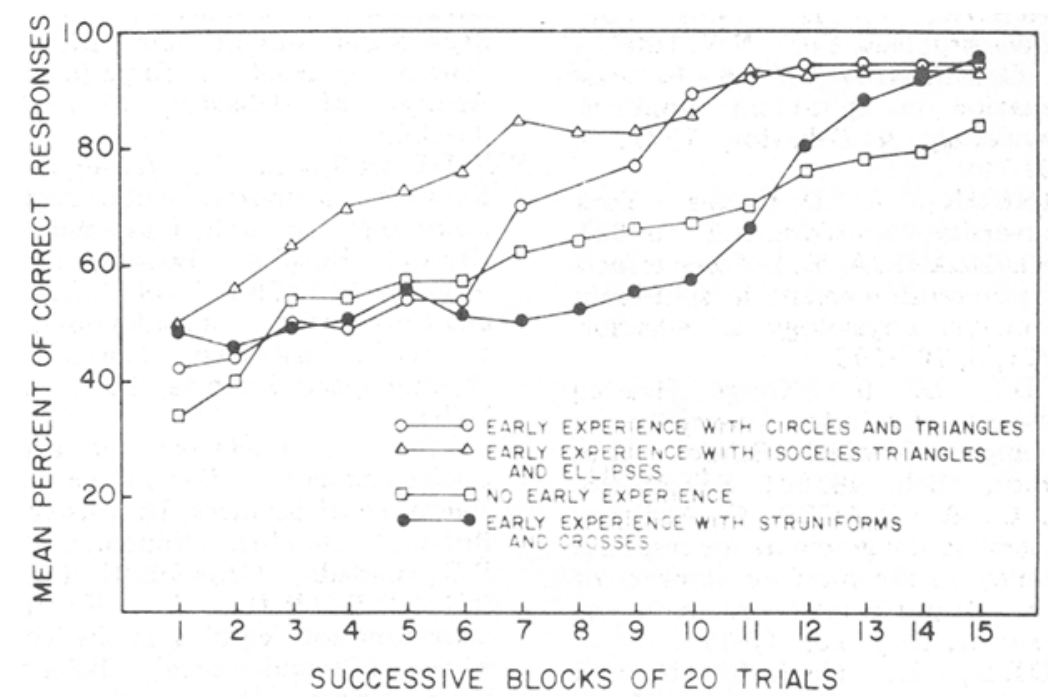

Fig. 1. Discrimination learning curves as a function of preexposure conditions. 
For the first five trial blocks, this group's performance was equivalent to the control group; however, during Trial Blocks 6-10, Group NR was inferior to Group C, a relationship which is later reversed during Blocks 12-15. Group NR exhibited similar performance levels to Groups I and $R$ during Trial Blocks 14 and 15 .

A Kruskal-Wallis one-way analysis of variance by ranks indicated $a$ significant difference between the groups in terms of the mean number of trials to reach criterion $[H(3)=13.26, p<.02]$. To isolate the significant source of variance, Mann-Whitney $U$ tests (two-tailed) were applied to assess differences between groups in terms of their trials to criterion. The results of these analyses are presented in Table 1. Examination of this table indicates that the performance of Groups I and $R$ was comparable and that both of these groups learned the discrimination task in fewer trials than did Group C. Similarly, Gibson, Walk, Pick, \& Tighe (1958) found that early experience with equilateral triangles and circles produced equivalent positive transfer to either an equilateral triangle-circle or isosceles triangle-ellipse discrimination problem.
Table 1

Summary of Mann-Whitney $U$ Tests Analyzing Trials to Criterion Between the $V$ arious Stimulus Preexposure Conditions

\begin{tabular}{lcll}
\hline Groups & df & U & \multicolumn{1}{c}{ p } \\
\hline I vs R & 11,13 & 62 & n.s. \\
I vs NR & 11,11 & 25 & $<.02$ \\
I vs C & 11,11 & 10 & $<.002$ \\
R vs NR & 13,11 & 55 & n.s. \\
R vs C & 13,11 & 30 & $<.02$ \\
NR vs C & 11,11 & 32 & n.s. \\
\hline
\end{tabular}

The present analysis also indicated that the performance of Group I was superior to Group NR and that this latter group did not learn the discrimination task at a faster rate than did Group C.

The results imply that for early experience to facilitate perceptual learning, the preexposed stimuli must be of the same general class as the to-be-discriminated stimuli. Preexposure to stimuli constructed from the same elements, straight and curved lines, but not of the same general family, i.e., triangles and circles, as the to-be-discriminated stimuli did not yield a positive transfer effect as compared to the performance of nonpreexposed control animals. In fact, as compared to the control animals, the Ss exposed to struniforms and crosses demonstrated a degree of negative transfer. The data shed light on the question of what is learned in the early environment that transfers to the later discrimination task. Specifically, the results suggest that the positive transfer effect which follows early stimulus experience results from identifying a fairly specific pattern rather than being due to a more general process of simply having had stimulus experience.

REFERENCES
BENNETT, T. L., \& ELLIS, H. C.
Tactual-kinesthetic feedback from
manipulation of visual forms and
nondifferential reinforcement in transfer
of perceptual learning. Journal of
Experimental Psychology, 1968, 77,
$495-500$.
GIBSON, E. J., \& WALK, R. D. The effect
of prolonged exposure to visually
presented patterns on learning to
discriminate them. Journal of
Comparative \& Physiological Psychology,
1956, 49, 239-242.
GIBSON, E. J., WALK, R. D., PICK, H.,
JR., \& TIGHE, T. J. The effect of
prolonged exposure to visual patterns on
learning to discriminate similar and
different patterns. Journal of
Comparative \& Physiological Psychology,
1958, $51,584-587$.
KERPELMAN, L. C. Preexposure to visually
presented forms and nondifferential
reinforcement in perceptual learning.
Journal of Experimental Psychology,
1965, 68, 257-262.

BENNETT, $T$. L., \& ELLIS, H. C manipulation of visual forms and nondifferential reinforcement in transfer Experimental Psychology, 1968, 77 495-500.

of prolonged exposure to visually presented patterns on learning to discriminate them. Journal o Comparative \& Physiological Psychology $1956,49,239-242$.

JR \& TIGHE $T$ J The effect of prolonged exposure to visual patterns on learning to discriminate similar and Comparative \& Physiological Psychology, $1,584-587$

presented forms and nondifferentia Journal of Experimental Psychology, $1965,68,25$ 7-262.

\section{CURRENT LITERATURE ON DISCRIMINATION LEARNING IN ANIMALS}

BOITANO, J. J. (Mount Holyoke College, South Hadley, Mass. 01075), PATRISSI, G. A., \& SIMONE, S. A. Effects of magnesium pemoline in dimethylsulfoxide on reversal learning, motor activity, and water intake. Psychological Reports, 1971, 28, 71-79.

JOHNSON, J. D. (New York University, New York, N.Y. 10003), \& GAZZANIGA, M. S. Reversal behavior in split-brain monkeys. Physiology \& Behavior, 1971, 6, 707-709.

JOHNSON, J. D. (New York University, New York, N.Y. 10003), \& GAZZANIGA, M. S. Some effects of non-reinforcement in split-brain monkeys. Physiology \& Behavior, 1971, 6, 703-706.

MOODY, D. B. (Kresge Hearing Research Institute, University of Michigan Medical School, Ann Arbor, Mich. 48104), STEBBINS, W. C., \& IGLAUER, C. Auditory generalization gradients for response latency in the monkey. Jounral of the Experimental Analysis of Behavior, 1971, 16, 105-111.

N A DEL, L. (M.R.C. Neural Mechanisms Research Unit,
University College London, Gower St., London W.C.1, England). Interhemispheric transfer: Monocular input and varied sensory conditions. Physiology \& Behavior, 1971, 6, 655-661.

POWELL, R. W. (Department of Behavioral Science, University of South Florida, Tampa, Fla. 33620). Evidence of interaction between deprivation effects and stimulus control. Journal of Experimental Analysis of Behavior, 1971, 16, 95-104.

STODDARD, L. T. (Joseph P. Kennedy Memorial Laboratories, Neurology Research, Massachusetts General Hospital, Boston, Mass. 02114), \& SIDMAN, M. Stimulus control after intradimensional discrimination training. Psychological Reports, 1971, 28, 147-157.

WHITE, D. (Cetacean Research Laboratory, Division of Neurological Sciences, University of British Columbia, Vancouver 8, B.C., Canada), CAMERON, N., \& B R A D O R D, J. Visual discrimination learning in the killer whale (Orcinus orca). Behavior Research Methods and
Instrumentation, 1971, 3, 187-188.

WLLIAMS, B. A. (Colorado College, Colorado Springs, Colo. 80903). Non spatial delayed alternation by the pigeon. Journal of the Experimental Analysis of Behavior, 1971, 16, 15-21.

WIMER, C. C. (Division of Neurosciences, City of Hope National Medical Center, Duarte, Calif. 91010), WIMER, R. E., \& RODERICK, T. H. Some behavioral differences associated with relative size of hippocampus in the mouse. Journal of Comparative $\&$ Physiological Psychology, 1971, 76, 57-65.

WRIGHT, D. G. (University of Missouri, Columbia, Mo. 65201), FRENCH, G. M., \& PINSKER, H. M. A semiautomated Wisconsin General Test Apparatus. Behavior Research Methods and Instrumentation, 1971, 3, 189-192.

YARCZOWER, M. (Bryn Mawr College, Bryn Mawr, Pa. 19010). Stimulus control during conditional discrimination. Journal of the Experimental Analysis of Behavior, $1971,16,89-94$. 